九州大学学術情報リポジトリ

Kyushu University Institutional Repository

\title{
Morphological Taxonomy of Musa Genotypes in Taiwan
}

CHANG, Shu-Fen

Institute of Tropical Agriculture, Kyushu University | Chiayi Agricultural Experiment Branch, Taiwan Agricultural Research Institute | Department of Horticultural Science, National Chiayi University

YEN, Yung-Fu

Institute of Tropical Agriculture, Kyushu University | Department of Horticultural Science, National Chiayi University

CHANG, Jer-Way

Institute of Tropical Agriculture, Kyushu University | Chiayi Agricultural Experiment Branch, Taiwan Agricultural Research Institute

MIYAJIMA, Ikuo

Institute of Tropical Agriculture, Kyushu University | Institute of Tropical Agriculture, Kyushu University

他

https://doi.org/10.5109/1909899

出版情報: 九州大学大学院農学研究院紀要. 63 (1)，pp.27-35，2018-02-27. Faculty of Agriculture， Kyushu University

バージョン :

権利関係 : 


\title{
Morphological Taxonomy of Musa Genotypes in Taiwan
}

\author{
Shu-Fen CHANG ${ }^{1,2}$, Yung-Fu YEN ${ }^{3}$, Jer-Way CHANG ${ }^{1}$, \\ Ikuo MIYAJIMA ${ }^{4}$ and Kuang-Liang HUANG ${ }^{2 *}$ \\ Institute of Tropical Agriculture, Kyushu University, \\ Fukuoka 812-8581, Japan \\ (Received October 30, 2017 and accepted November 20, 2017)
}

\begin{abstract}
This paper presents the morphological classification of 19 Musa species and cultivars. Fifteen morphological characters for Musa acuminata and M. balbisiana and 50 morphological characters adapted from International Union for the Protection of New Varieties of Plant (UPOV) codes were employed to elucidate the phylogenetic relationship between both banana species. Analyses of genetic similarity based on all of these morphological characters suggested that bananas with A-genomes were in the same cluster. Moreover, a genetic similarity coefficient of 0.36 was obtained between $M$. acuminata and M. balbisiana in the analysis with the 15 morphological characters for both species, and 0.47 in the analysis with 50 UPOV-based morphological characters. Moreover, principal component analysis (PCA) of the 15 morphological characters suggested that PC1 and PC2 together explained $78.6 \%$ of the total variance. A PCA with 50 UPOV-based morphological characters indicated that PC1 explained 80.6\% of the total variance, for which the main variables were pseudostem length, leaf blade length, and peduncle length. PCA of the 15 morphological characters showed that 'Pei Chiao', 'Giant Cavendish', and 'Dwarf Cavendish' were proximal in the PCA scatterplot. Notably, the PCA of 50 UPOV-based morphological characters indicated that 'Pei Chiao' and 'Giant Cavendish' were near each other in the PCA scatterplot, suggesting that they are phylogenetically related. The PCA of $M$. itinerans var. formosana with 15 morphological descriptors showed that this variant is phylogenetically distant from $M$. acuminata and $M$. balbisiana accessions. In summary, the findings may contribute to the classification and breeding of banana germplasm.
\end{abstract}

Key words: Musa, banana, morphological characterization, Musa, principal component analysis

\section{INTRODUCTION}

Banana (Musa spp.) is a perennial herbaceous plant of the family Musaceae and a major tropical fruit. Worldwide, the production of banana amounts to 114 million tons, and the area harvested for the fruit is approximately 5 million hectares (FAO, 2014). Musa spp. descends from Musa acuminata Colla (A genome) and M. balbisiana Colla (B genome) and evolve through hybridization into a diploid ( $\mathrm{AB}$ ), triploids (AAA, $\mathrm{AAB}$, and $\mathrm{ABB}$ ), and tetraploids (AAAA, $\mathrm{AAAB}, \mathrm{AABB}, \mathrm{ABBB}$ ) (Simmonds and Shepherd, 1955); commercial banana cultivars are predominantly triploids. Dessert and cooking bananas, both of which are triploids, are one of the world's most important fruit crops, and the Cavendish subgroup, which comprises triploid bananas, accounts for $47 \%$ of the global banana production (FAO, 2003). In Taiwan, most banana cultivars are Cavendish banana cv. Formosana, which is locally known as 'Pei Chiao' and belongs to the Cavendish subgroup. Subgroups are cultivated varieties derived from somatic mutation and characterized by little genetic diversity (Channelie're et

${ }^{1}$ Chiayi Agricultural Experiment Branch, Taiwan Agricultural Research Institute, COA, Chiayi 60014, Taiwan, Republic of China

${ }^{2}$ Department of Horticultural Science, National Chiayi University, Chiayi 60004, Taiwan, Republic of China

${ }^{3}$ Department of BioAgricultural Science, National Chiayi University, Chiayi 60004, Taiwan, Republic of China

${ }^{4}$ Institute of Tropical Agriculture, Kyushu University, Fukuoka 812-8581, Japan

* Corresponding author: (E-mail: klhuang@mail.ncyu.edu.tw) al., 2011). M. acuminata includes subspecies and exhibits larger phenotypic variation (De Langhe, 2000).

Bananas are mostly sterile, because they yield fruit by parthenocarpy, produce no seed (Swennen et al., 1995). They reproduce asexually, and their somatic mutation occurs separately in different progenitor clones, rendering morphological classification difficult (Onyango et al., 2011). Simmonds and Shepherd (1955) established the first morphological characterization of $M$. acuminata and $M$. balbisiana to classify different bananas in different genome groups, and their characterization system has been widely used (De Langhe, 2000). $\mathrm{AA}, \mathrm{BB}, \mathrm{AB}, \mathrm{AAA}, \mathrm{AAB}, \mathrm{AAAA}, \mathrm{AAAB}$, and $\mathrm{AABB}$ bananas, as well as some wild species, are evaluated using quantitative and qualitative descriptors (Ortiz, 1997). IPGRI-INIBAP/CIRAD (1996) has developed descriptors for Musa spp. Onyango et al. (2011) derived 84 characters of $\mathrm{AAB}$ and $\mathrm{AA}$ dessert bananas in East Africa from modified descriptors for bananas developed by Bioversity International and CIRAD, and divided Musa acuminataderived cultivars (AAs and AAAs) and hybrids between M. balbisiana and M. acuminata (AAB) into two separate clusters. They found that 33 of the characters contributed to $71 \%$ of the total variance. Descriptors for germplasm characterization are essential to morphological classification, and morphological descriptors should have high heritability and low genotype-by-environment interaction (Ortiz, 1997).

Characterization data can be used in Musa conservation; therefore, comprehensively characterizing and documenting Musa genetic diversity can contribute to germplasm conservation, the availability of diversity for culti- 
vation, and breeding programs (Channelie're et al., 2011). Plants provide essential nutrients for humans. Modern agricultural techniques enable breeders to grow varieties that are resistant to environmental stresses (e.g., pollutants, droughts, and diseases), high-yield, or with superior mouthfeel or enriched color. Breeding renders Musa spp. resistant to environmental stress and disease (e.g., Fusarium wilt, black leaf streak, and banana streak virus). The genepool provides an abundance of Musa germplasm with disease resistances, abiotic stress resistances, and altered agronomic performance (HeslopHarrison and Schwarzacher, 2007). New cultivars must be patented to safeguard breeders' rights to the cultivars and formulate the rules of usage; therefore, minimum efficient descriptors should be established to facilitate the distinction of the cultivars (Brandao et al., 2013). The International Union for the Protection of New Varieties of Plants (UPOV) has established a system of plant variety protection, with the aim of "encouraging the development of new varieties of plants, for the benefit of society" (Byrne, 1993). UPOV (2010) has defined 52 Musa spp. characters, and it uses them to identify new banana species and determine their novelty and uniqueness.

The genetic identity and phylogenetic relationship of a cultivar or species are increasingly important to breeders in the terms of protection of their rights to new cultivars or species; moreover, morphological descriptors are preferably applied in varietal identification (Singh et al., 2015). The morphological characterization of bananas entails measuring various morphological traits of germplasm collections; univariate analysis and principal component analysis (PCA) are typically performed to identify descriptors that are crucial to characterizing and classifying Musa germplasm collections (Ortiz, 1997). Furthermore, PCA is more suitable than univariate analysis for revealing the relationships between characters (Iezzoni and Pritts, 1991). The present study conducted a PCA of the characters of banana germplasm collections in Taiwan to investigate the genetic diversity of the germplasm collections and their phylogenetic relationship.

\section{MATERIALS AND METHODS}

\section{Plant materials}

This study used 19 Musa species and cultivars (two M. acuminata materials, two $M$. balbisiana materials, 14 intra- or interspecific hybrids of $M$. acuminata and $M$. balbisiana, and one species of $M$. itinerans var. formosana) cultivated in a banana germplasm garden managed by the Taiwan Agricultural Research Institute (Chiayi branch) (Table 1). The geographic coordinates of the garden are $23^{\circ} 48^{\prime} 43^{\prime \prime} \mathrm{N}$ and $120^{\circ} 46^{\prime} 80^{\prime \prime} \mathrm{E}$. It is at an elevation of $33 \mathrm{~m}$ with an average annual temperature of $23^{\circ} \mathrm{C}$ and an average annual precipitation of $2000 \mathrm{~mm}$.

Table 1. Plant materials of genus Musa used in this study

\begin{tabular}{|c|c|c|c|c|c|}
\hline No. & Accession ID ${ }^{\mathrm{a}}$ & Species/hybrid & Genome & Common name & Abbreviation \\
\hline 1 & 00264380 & M. acuminata & $\mathrm{AA} \mathrm{w}^{\mathrm{b}}$ & M. acuminata & $\mathrm{ACU}$ \\
\hline 2 & 00105288 & M. acuminata & $\mathrm{AA} \mathrm{cV}^{\mathrm{b}}$ & Sucrier & SUC \\
\hline 3 & 00105297 & M. acuminata $\times M$. balbisiana & $\mathrm{AB}$ & Ney Poovan & $\mathrm{NPO}$ \\
\hline 4 & 00105304 & M. balbisiana & $\mathrm{BB} \mathrm{w}^{\mathrm{c}}$ & M. balbisiana & BAL \\
\hline 5 & 00105411 & M. acuminata (Triploid) & AAA & Dwarf Cavendish & DCA \\
\hline 6 & 00105466 & M. acuminata (Triploid) & $\mathrm{AAA}$ & Giant Cavendish & GCA \\
\hline 7 & 00105671 & M. acuminata (Triploid) & AAA & Morado & MOR \\
\hline 8 & 00106025 & M. acuminata (Triploid) & AAA & Pei Chiao & $\mathrm{PCH}$ \\
\hline 9 & 00264577 & M. acuminata (Triploid) & AAA & Yangambi KM5 & YAN \\
\hline 10 & 00106043 & M. acuminata $\times M$. balbisiana (Triploid) & $\mathrm{AAB}$ & Assam & ASS \\
\hline 11 & 00264700 & M. acuminata $\times M$. balbisiana (Triploid) & $\mathrm{AAB}$ & Rilian & RIL \\
\hline 12 & 00264835 & M. acuminata $\times M$. balbisiana (Triploid) & $\mathrm{ABB}$ & Ice Cream & ICR \\
\hline 13 & 00264844 & M. acuminata $\times M$. balbisiana (Triploid) & $\mathrm{ABB}$ & Monkey & MON \\
\hline 14 & 00264853 & M. balbisiana (Triploid) & $\mathrm{ABB}$ & Nibah & NIB \\
\hline 15 & 00264335 & M. acuminata $\times M$. balbisiana (Triploid) & $\mathrm{ABB}$ & Pelipita & PEL \\
\hline 16 & 00264826 & M. balbisiana (Triploid) & $\mathrm{BBB}$ & Cooking & $\mathrm{COO}$ \\
\hline 17 & 00264522 & M. acuminata (Tetraploid) & AAAA & Fhia-17 & $\mathrm{F}-17$ \\
\hline 18 & 00264497 & M. acuminata $\times M$. balbisiana (Tetraploid) & $\mathrm{AAAB}$ & Fhia-01 & $\mathrm{F}-01$ \\
\hline 19 & 00105242 & M. itinerans & unknown & Formosana & FOR \\
\hline
\end{tabular}

${ }^{a}$ Accession ID was based on the National Plant Genetic Resources Center of Taiwan Agricultural Research Institute.

${ }^{\mathrm{b}} M$. acuminata $A A w$ wild type, $A A c v$ cultivar

${ }^{c} M$. balbisiana $B B w$ wild type 


\section{Morphological characterization}

Simmondsm and Shepherd (1955) proposed 15 morphological characters for M. acuminata and M. balbisiana (i.e., pseudostem color, petiolar canal, peduncle, pedicel, ovule, bract shoulder, bract curling, bract shape, bract apex, bract color, color fading, bract scar, free tepal of male flower, male flower color, and stigma color) to classify banana cultivars and assess them by the score of 1 (M. acuminata character) or 2 (M. balbiaiana character). Table 2 and Fig. 1 show the 15 morphological characters.
Fifty morphological characters have been adapted for assessment from UPOV codes for $M$. acuminata Colla; M. x paradisiaca L. (UPVO, 2010). These characters are presented in Table 3 . Among them, 6 are qualitative, 31 quantitative, and 13 pseudo-qualitative. Each of the characters is assessed with a score from 1 to 9 .

\section{Data analysis}

NTSYSpc 2.2 was used to measure the genetic similarity of samples, the purpose of which was to collect data on their morphological characters (Rohlf, 2006). Next,

Table 2. Characters found most variable based on first four principal components, derived from morphological characters for M. acuminata and M. balbisiana

\begin{tabular}{lcccc}
\hline \multirow{2}{*}{ Character } & \multicolumn{4}{c}{ Principal components } \\
\cline { 2 - 5 } & 1 & 2 & 3 & \multicolumn{1}{c}{0.149} \\
\hline Pseudostem color & 0.267 & 0.204 & 0.309 & -0.334 \\
Petiolar canal & 0.307 & -0.096 & -0.049 & -0.334 \\
Peduncle & 0.307 & -0.096 & -0.049 & -0.047 \\
Pedicels & 0.348 & 0.803 & -0.402 & -0.327 \\
Ovules & 0.251 & 0.086 & 0.319 & -0.015 \\
Bract shoulder & 0.022 & -0.041 & -0.023 & -0.014 \\
Bract curling & 0.039 & -0.055 & 0.183 & 0.299 \\
Bract shape & 0.302 & -0.129 & 0.022 & 0.122 \\
Bract apex & 0.265 & -0.298 & -0.215 & -0.008 \\
Bract color & 0.282 & -0.252 & -0.150 & 0.036 \\
Color fading & 0.310 & -0.187 & -0.133 & 0.221 \\
Bract scare & 0.106 & 0.121 & 0.534 & -0.328 \\
Free tepal of male flower & 0.206 & 0.004 & 0.447 & -0.008 \\
Male flower color & 0.282 & -0.252 & -0.150 & 0.618 \\
Stigma color & 0.290 & 0.035 & 0.097 & \\
\hline
\end{tabular}
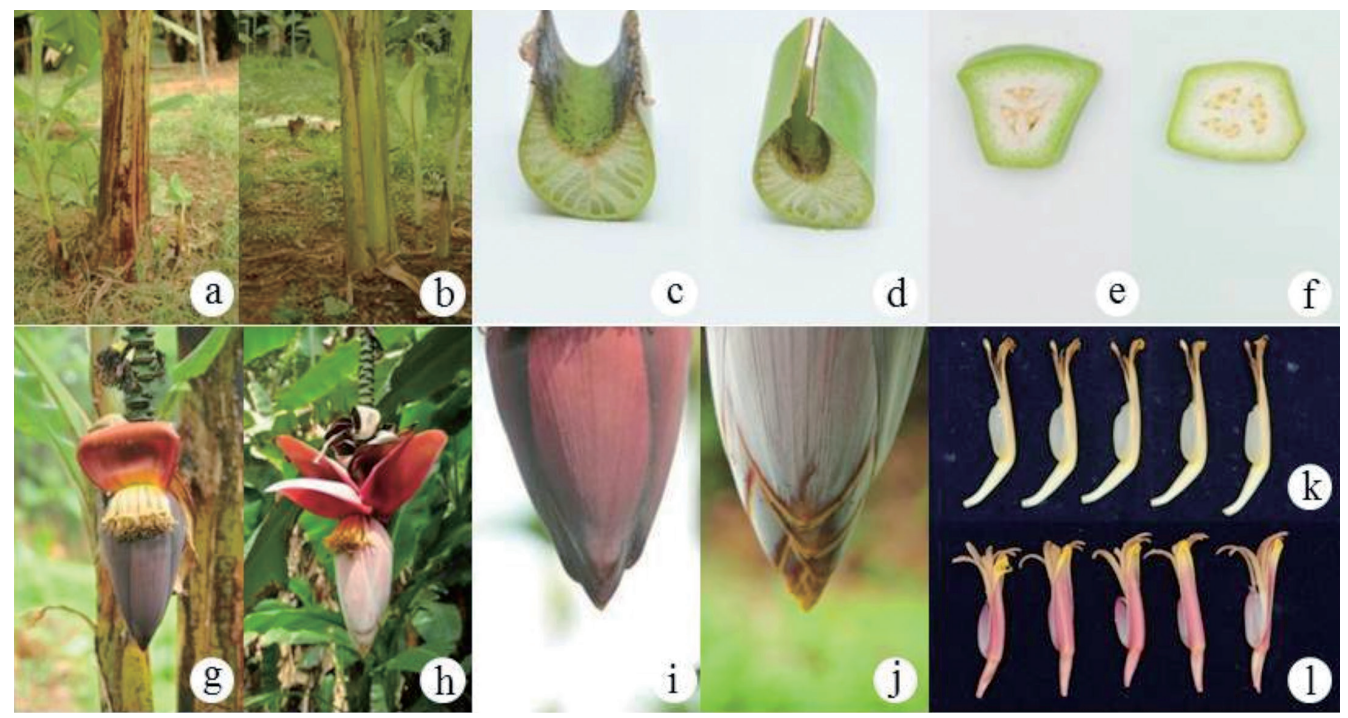

Fig. 1. Morphological traits of various banana accessions used in the scoring of bananas. (a) Pseudostem color: more or less heavily marked with brown of black blotches. (b) Pseudostem color: blotches very slight or absent. (c) Petiole: open canal. (d) Petiole: closed canal. (e) Ovule: two regular rows of ovules. (f) Ovule: four irregular rows of ovules. (g) Bract scare: prominent. Bract: curl. (h) Bract scare: scarcely prominent. Bract: not curl. (i) Bract apex: acute. (j) Bract apex: obtuse. (k) Male flower color: creamy white. (l) Male flower color: variably flushed with pink. 
Table 3. Characters found most variable based on first four principal components, derived from morphological characters adapted from the UPOV codes

\begin{tabular}{|c|c|c|c|c|}
\hline \multirow{2}{*}{ Character } & \multicolumn{4}{|c|}{ Principal components } \\
\hline & 1 & 2 & 3 & 4 \\
\hline Ploidy & 0.001 & 0.006 & 0.007 & 0.009 \\
\hline Rhizome: number of suckers above ground & 0.004 & 0.016 & -0.013 & -0.010 \\
\hline Pseudostem: length & 0.941 & -0.287 & -0.134 & 0.075 \\
\hline Pseudostem: diameter & 0.047 & 0.075 & -0.058 & 0.092 \\
\hline Pseudostem: tapering along length & 0 & 0 & 0 & 0 \\
\hline Pseudostem: color & -0.009 & -0.012 & -0.008 & 0.014 \\
\hline Pseudostem: intensity of anthocyanin coloration & -0.014 & 0.025 & 0.015 & -0.022 \\
\hline Pseudostem: color of the inner side of sheath base & 0 & 0 & 0 & 0 \\
\hline Plant: compactness of crown & 0 & 0 & 0 & 0 \\
\hline Plant: growth habit & 0 & 0 & 0 & 0 \\
\hline Petiole: attitude of wings at base & 0.009 & -0.011 & -0.002 & 0.001 \\
\hline Petiole: length & 0.025 & -0.099 & 0.202 & -0.267 \\
\hline Leaf blade: color of midrib on lower side & 0.001 & 0 & 0 & 0 \\
\hline Leaf blade: shape of base & -0.005 & -0.006 & -0.004 & 0.007 \\
\hline Leaf blade: waxiness on lower side & -0.002 & 0.012 & -0.061 & 0.057 \\
\hline Leaf blade: length & 0.282 & 0.550 & 0.370 & -0.636 \\
\hline Leaf blade: width & 0.035 & 0.374 & -0.043 & 0.124 \\
\hline Leaf blade: ratio length/width & 0.002 & -0.006 & 0 & 0 \\
\hline Leaf blade: glossiness of upper side & -0.007 & -0.062 & 0.057 & -0.090 \\
\hline Peduncle: length & 0.128 & 0.348 & 0.414 & 0.554 \\
\hline Peduncle: diameter & 0.007 & 0.020 & -0.007 & -0.004 \\
\hline Peduncle: pubescence & -0.031 & 0.015 & 0.014 & -0.036 \\
\hline Peduncle: curvature & 0.003 & 0.021 & 0.013 & 0.032 \\
\hline Bunch: length & 0.099 & 0.325 & 0.065 & 0.338 \\
\hline Bunch: diameter & 0.028 & 0.130 & -0.081 & 0.130 \\
\hline Bunch: shape & 0 & 0 & 0 & 0 \\
\hline Bunch: attitude of fruits & 0.003 & 0.006 & 0.003 & 0 \\
\hline Bunch: compactness & 0 & 0 & 0 & 0 \\
\hline Bunch: number of hands & 0.009 & 0 & 0 & 0 \\
\hline Rachis: attitude of male part & -0.003 & -0.005 & -0.003 & 0 \\
\hline Rachis: prominence of scars & 0.005 & 0 & 0 & 0 \\
\hline Rachis: persistence of bracts & -0.002 & 0 & 0 & 0 \\
\hline Rachis: persistence of hermaphrodite flowers & 0.002 & 0 & 0.015 & 0.063 \\
\hline Fruit: longitudinal curvature & -0.003 & 0.009 & 0.005 & 0 \\
\hline Fruit: longitudinal ridges & 0.003 & -0.007 & -0.004 & 0 \\
\hline Fruit: length & 0.007 & 0.079 & -0.033 & 0.158 \\
\hline Fruit: width (excluding ridges) & 0.003 & 0.008 & 0.004 & 0 \\
\hline Fruit: length of pedicel & 0.006 & 0 & 0 & 0 \\
\hline Fruit: shape of apex & 0 & 0 & 0 & 0 \\
\hline Fruit: thickness of peel & 0 & 0 & 0 & 0 \\
\hline Fruit: color of peel (before maturity) & -0.008 & 0 & 0 & 0 \\
\hline Fruit: color of peel & -0.003 & -0.034 & -0.019 & -0.027 \\
\hline Fruit: persistence of floral organs & -0.018 & -0.017 & 0.013 & 0.001 \\
\hline Fruit: color of flesh & -0.006 & 0.012 & 0.006 & 0 \\
\hline Fruit: firmness of flesh & -0.045 & -0.450 & 0.779 & 0.106 \\
\hline Male inflorescence: persistence & -0.002 & 0 & 0 & 0 \\
\hline Male inflorescence: shape (in cross section) & 0.002 & 0 & 0 & 0 \\
\hline Male inflorescence: overlap of bracts & -0.005 & 0.007 & 0 & 0 \\
\hline Bract: color of inner side & 0.002 & 0.012 & 0.001 & 0.041 \\
\hline Male inflorescence: shape of apex of bract & 0.008 & -0.006 & 0 & 0 \\
\hline
\end{tabular}


the unweighted pair-group method with arithmetic mean (UPGMA) was employed to conduct a clustering analysis of their genetic similarity and to plot a phylogenetic dendrogram. PCA was subsequently performed to identify possible relationships between the samples (Iezzoni and Pritts, 1991) and generate biplots in accordance with the morphological characterization of the samples (Osuji et al., 1997).

\section{RESULTS}

\section{Genetic diversity analysis}

Fig. 2a shows the results of the UPGMA analysis of the genetic similarity of the samples based on Simmondsm and Shepherd's (1955) 15 morphological characters of $M$. acuminata and $M$. balbisiana. The results suggested that the eight $M$. acuminata species, three $M$. balbisiana species, and seven of their hybrids belonged to different clusters and had a significant genetic distance (genetic similarity coefficient $=0.36$ ) . The analysis yielded two clusters. Cluster 1 comprised 2 subclusters, and Subcluster 1 consisted of $M$. acumi- nata, 'Sucrier', 'Yangambi KM5', 'Giant Cavendish', 'Dwarf Cavendish', 'Pei Chiao', 'Morado', and 'Fhia-17' (genetic similarity coefficient $=0.85)$; whereas Subcluster 2 spanned $M$. itinerans var. formosana (genetic similarity coefficient $=0.79$ with Subcluster 1 ). Similarly, Cluster 2 comprised 2 subclusters. Subcluster 1 spanned 'Ney Poovan', 'Assam', 'Rilian', and 'Fhia-01' (genetic similarity coefficient $=0.80$ ); whereas Subcluster 2 encompassed M. balbisiana, 'Cooking', 'Ice Cream', 'Monkey', 'Nibah', and 'Pelipita' (genetic similarity coefficient $=0.85$ ).

Moreover, all banana species in Subcluster 1 of Cluster 1 belonged to A-genome groups-that is, AA diploids ( $M$. acuminata and 'Sucrier'), AAA triploids ('Yangambi KM5', 'Giant Cavendish', 'Dwarf Cavendish', 'Pei Chiao', and 'Morado'), and an AAAA tetraploid (Fhia17). Except for Moraod, all the other 7 species had a genetic similarity coefficient of 0.93 (Fig. 2a).

Fig. $2 \mathrm{~b}$ presents the UPGMA analysis results on the genetic similarity of samples based on 50 morphological characters adapted for assessment from the UPOV codes for M. acuminata Colla; M. x paradisiaca L. The results indicated that the respective species of $M$. acumi-

(a)

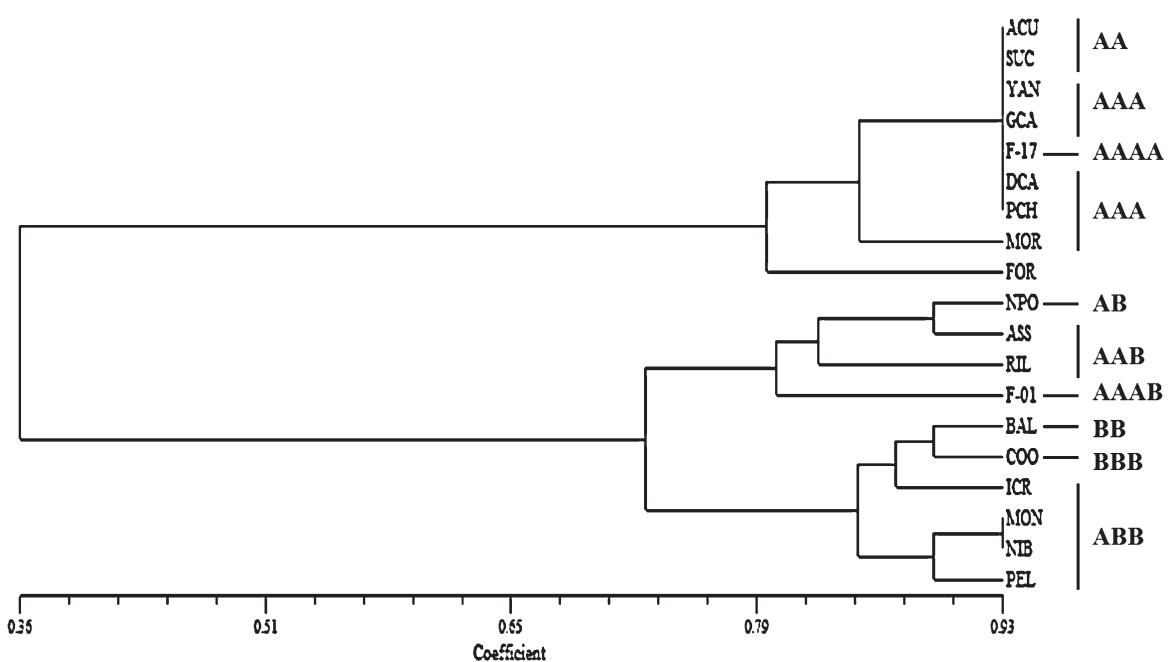
Coesficient

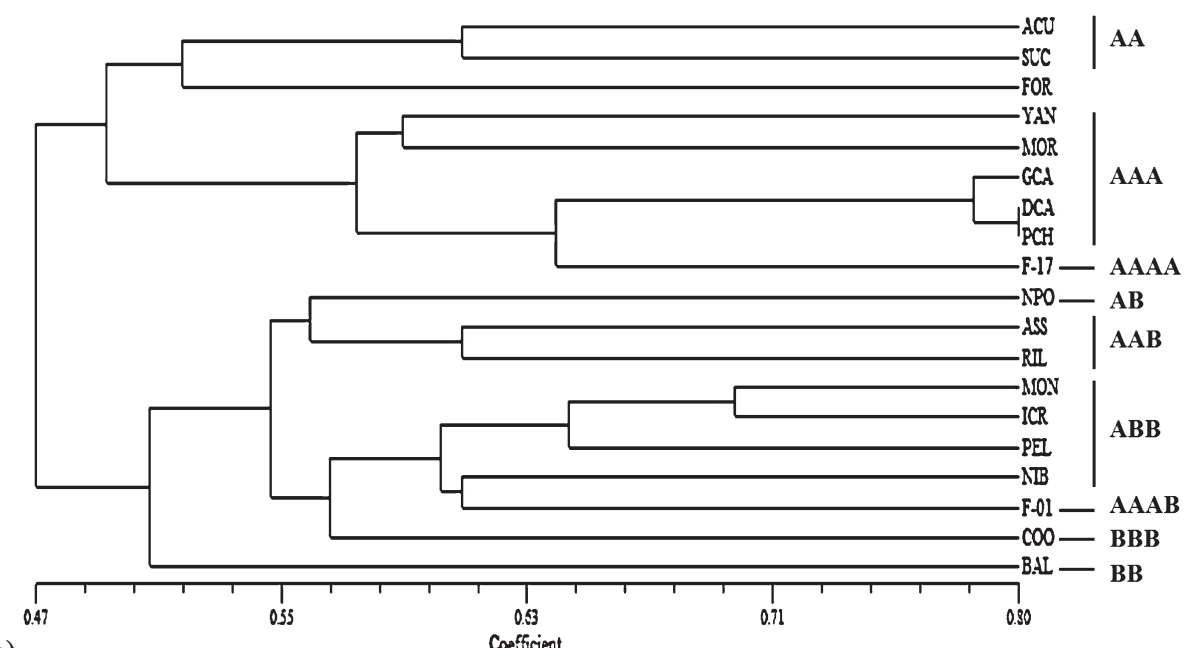

(b)

Fig. 2. Dendrogram of genetic similarities in Musa, a (above): obtained through morphological characters for $M$. acuminata and $M$. balbisiana, $\mathrm{b}$ (below): obtained through morphological characters adapted from the UPOV codes. 
nata and M. balbisiana and their hybrids belonged to different clusters and had a significant genetic distance (genetic similarity coefficient $=0.47$ ). The analysis yielded two clusters. Cluster 1 comprised 2 subclusters, and Subcluster 1 was divided into two subordinate subclusters. Subordinate subcluster 1 spanned two AA diploids, M. acuminata and 'Sucrier' (genetic similarity coefficient $=0.61$ ); whereas Subordinate subcluster 2 included $M$. itinerans var. formosana (genetic similarity coefficient $=0.52$ with Subordinate subcluster 1 ). Subcluster 2 consisted of 'Yangambi KM5', 'Morad', 'Giant Cavendish', 'Dwarf Cavendish', 'Pei Chiao', and 'Fhia-17' (genetic similarity coefficient $=0.58$ ). Cluster 2 comprised 3 subclusters. Subcluster 1 spanned 'Ney Poovan', 'Assam', and 'Rilian' (genetic similarity coefficient = 0.56). Subcluster 2 spanned 'Monkey', 'Ice Cream', 'Pelipita', 'Nibah', 'Fhia-01', and 'Cooking' (genetic similarity coefficient $=0.57)$. Subcluster 3 encompassed a BB diploid, $M$. balbisiana (genetic similarity coefficient
$=0.5$ with the previous two subclusters).

In addition, all banana species in Subcluster 2 of Cluster 1 belonged to A-genome groups-that is, AAA triploids ('Yangambi KM5', 'Morado', 'Giant Cavendish', 'Dwarf Cavendish', 'Pei Chiao') and an AAAA tetraploid ('Fhia-17') (genetic similarity coefficient $=0.58$ ) (Fig. 2b).

\section{Principal component analysis}

The PCA based on the 15 morphological characters of $M$. acuminata and $M$. balbisiana showed that the cumulative variance was $64 \%$ for $\mathrm{PC} 1,78.6 \%$ for $\mathrm{PC} 2$, 87.6\% for PC3, and 91.4\% for PC4. PC1 explained 64\% of the total variance. Major variables in PC1 were pseudostem color, petiolar canal, peduncle, pedicel, ovule, bract shape, bract apex, bract color, color fading, bract scar, free tepal of male flower, male flower color, and stigma color. PC2 explained $14.6 \%$ of the total variance. These results are shown in Table 2. Moreover, the PCA

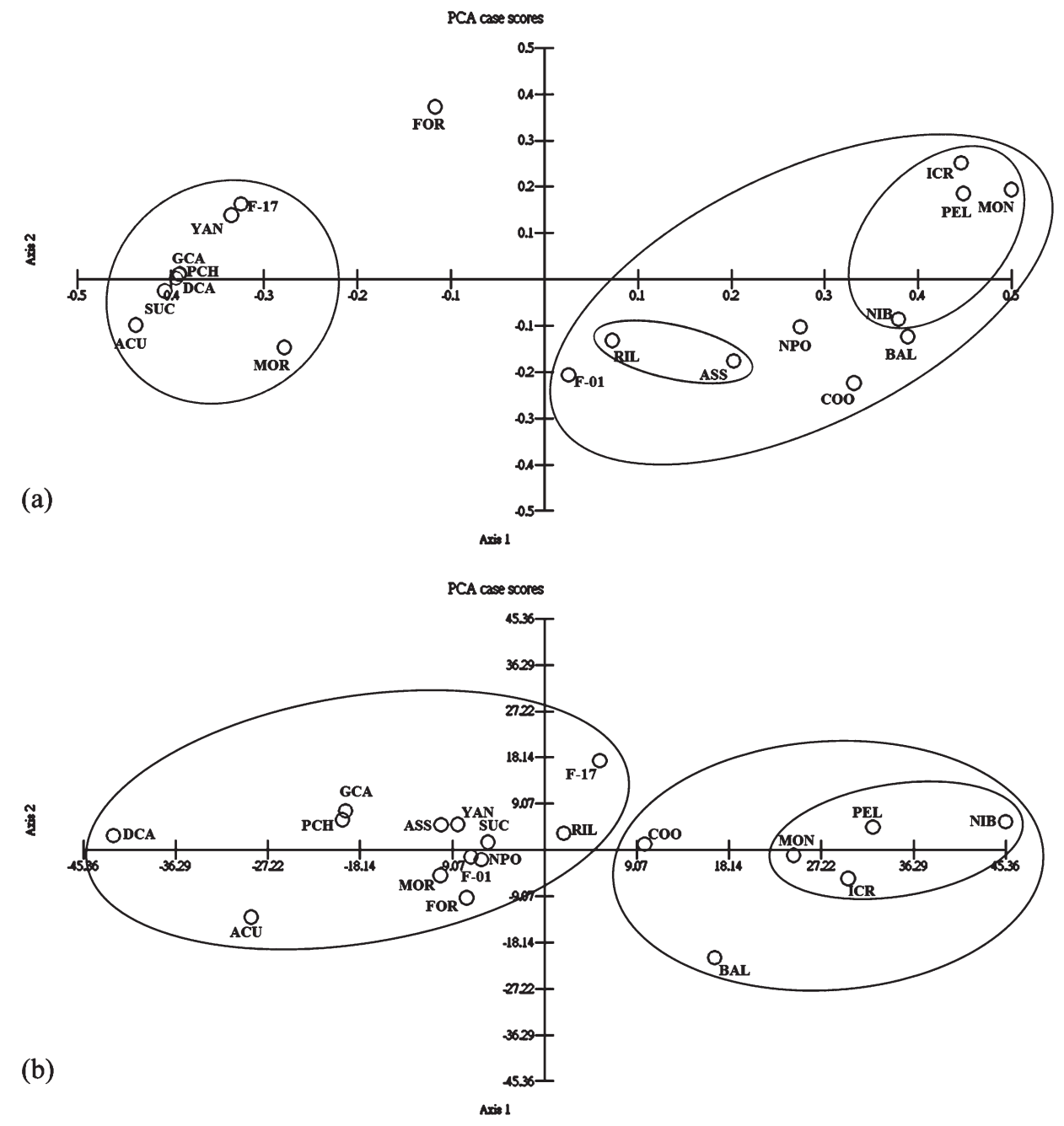

Fig. 3. Scatter plot of the PCA of the 19 Musa accessions, a (above): derived from morphological characters for $M$. acuminata and $M$. balbisiana, b (below): derived from morphological characters adapted from the UPOV codes.

(ACU: M. acuminata; ASS: 'Assam'; BAL: M. balbisiana; COO: 'Cooking'; DCA: 'Dwarf Cavendish'; F-01: 'Fhia-01'; F-17: 'Fhia-17'; FOR: 'Formosana'; GCA: 'Giant Cavendish'; ICR: 'Ice Cream'; MON: 'Monkey'; MOR: 'Morado'; NIB: 'Nibah'; NPO: 'Ney Poovan'; PCH: 'Pei Chiao'; PEL: 'Pelipita'; RIL: 'Rilian'; SUC: 'Sucrier'; YAN: 'Yangambi KM5') 
divided the respective species of $M$. acuminata and $M$. balbisiana and their hybrids into two 2-dimensional clusters (Fig. 3a). Cluster 1 spanned AA, AAA, and AAAA accessions (e.g., M. acuminata, 'Sucrier', 'Yangambi KM5', 'Morado', 'Pei Chiao', 'Giant Cavendish', 'Dwarf Cavendish', and 'Fhia-17'); in particular, 'Pei Chiao', 'Giant Cavendish', and 'Dwarf Cavendish' were near each other in the PCA scatterplot. Cluster 2 spanned $\mathrm{B}, \mathrm{BB}, \mathrm{AAB}, \mathrm{ABB}, \mathrm{BBB}$, and $\mathrm{AAAB}$ accessions (e.g., M. balbisiana, 'Ney Poovan', 'Assam', 'Rilian', 'Ice Cream', 'Monkey', 'Nibah', 'Pelipita', 'Cooking', and 'Fhia01'). Notably, 'Assam' and 'Rilian', both of which are AAB triploids, were near each other in the PCA scatterplot. 'Ice Cream', 'Monkey', 'Pelipita', and 'Nibah'-all of which are ABB triploids-were near each other in the PCA scatterplot. M. itinerans var. formosana did not belong to either cluster.

The PCA based on the 50 morphological characters adapted for assessment from the UPOV codes for $M$. acuminata Colla; M. x paradisiaca L. indicated that PC1 explained $80.6 \%$ of the total variance, accounting for most of the variation in the dataset. Major variables in PC1 were pseudostem length, leaf blade length, and peduncle length. PC2 explained $11.8 \%$ of the total variance (cumulative variance $=92.4 \%$ ). Major variables in PC2 were pseudostem length, leaf blade length, leaf blade width, peduncle length, bunch length, bunch diameter, and fruit flesh firmness. These results are summarized in Table 3. Furthermore, the PCA divided the respective species of $M$. acuminata and $M$. balbisiana and their hybrids into two 2-dimensional clusters (Fig. 3b). Cluster 1 spanned AA, AAA, AAAA, AB, AAB, and AAAB accessions (e.g., M. acuminata, 'Sucrier', 'Yangambi KM5', 'Morado', 'Pei Chiao', 'Giant Cavendish', 'Dwarf Cavendish', 'Fhia-17', 'Ney Poovan', 'Assam', 'Rilian', 'Ice Cream', and $M$. itinerans var. formosana). Notably, 'Pei Chiao' and 'Giant Cavendish' were near each other in the PCA scatterplot. Cluster 2 spanned BB, ABB, and BBB accessions (e.g., 'Ice Cream', 'Monkey', 'Nibah', 'Pelipita', 'Cooking', and 'Fhia-01'). 'Ice Cream', 'Monkey', 'Nibah', and 'Pelipita' - all of which are ABB triploidswere close to each other in the PCA scatterplot.

\section{DISCUSSION}

From the analysis of phylogenetic relationship between 19 Musa accessions and the UPGMA analysis of the genetic similarity of the accessions based on the 15 qualitative morphological descriptors for $M$. acuminata and $M$. balbisiana, the results indicate that species in the A-genome groups belong to the same cluster (Fig. 2a). However, AA, AAA, and AAAA accessions (e.g., $M$. acuminata, 'Sucrier', 'Yangambi KM5', 'Pei Chiao', 'Giant Cavendish', 'Dwarf Cavendish', and 'Fhia-17') could not be clustered, and each accession had a genetic similarity coefficient of 0.93. Moreover, the analysis results drawn from the 50 morphological characters adapted from the UPOV codes also suggests that banana species in the Agenome groups were in the same cluster (with AA, AAA, and AAAA accessions divided into distinct subclusters and subordinate subclusters), and $\mathrm{AB}, \mathrm{BB}, \mathrm{AAB}, \mathrm{ABB}$, $\mathrm{BBB}$, and $\mathrm{AAAB}$ accession were in another cluster (Fig. 2b). Characterization can be used to assess banana germplasm collections (Nsabimana and Staden, 2005). Therefore, characters of taxonomic relevance that are not subject to environmental factors or the year of cultivation are essential to banana classification (De Langhe et al., 2005). Quantitative and multicategory morphoagronomic descriptors are typically adopted to examine the genetic similarity of Musa spp. accessions, and reducing the number of descriptors used to characterize Musa spp. germplasm does not affect the estimation of genetic variability between Musa spp. germplasm (Brandão et al., 2013).

The results of the PCA based on the 15 qualitative morphological descriptors showed that PC1 and PC2 cumulatively explained $78.6 \%$ of the total variance. Qualitative morphological descriptors have been extensively used to classify different Musa germplasm collections under taxonomic groups with similar characters (Simmond and Shepherd, 1955; Tezenas du Montcel et al., 1983). Moreover, the results of the PCA with the 50 morphological characters adapted from the UPOV codes indicated that PC1 explained $80.6 \%$ of the total variance, and major variables in PC1 were pseudostem length, leaf blade length, and peduncle length. Onyango et al. (2011) analyzed 33 characters of AAB and AA dessert bananas in East Africa and found that PC1 and PC2 explained $71 \%$ of the total variance; moreover, their findings suggested that morphological characters can be used to distinguish between the genomes and subgroups of Musa spp. germplasm and to characterize Musa spp. subgroups. Quantitative continuous characters are employed to assess plantains and bananas (Ortiz and Vuylsteke, 1998). Primary quantitative descriptors for Musa germplasm collections include pseudostem girth, the number of fruits, and fruit size; such descriptors have high heritability, high repeatability, and low coefficients of variation (Ortiz, 1997).

'Pei Chiao' (Cavendish banana cv. Formosana) (Ko et al., 2009), 'Giant Cavendish', and 'Dwarf Cavendish'all of which are major banana cultivars in Taiwan-are Cavendish varieties with the AAA genome. A UPGMA analysis of the genetic similarity of the three banana cultivars based on the 50 UPOV-derived morphological characters showed that the genetic similarity coefficient was 0.8 for 'Dwarf Cavendish' and 0.78 for 'Giant Cavendish'. Moreover, an analysis of 21 primer pairs of 'Pei Chiao' and 'Dwarf Cavendish' through amplified fragment length polymorphism (AFLP) showed that the genetic similarity coefficient between these cultivars was 0.97. Both share a close phylogenetic relationship with 'Giant Cavendish', the genetic similarity coefficient among three cultivars being 0.99 (Chang et al., 2017). Indeed, the PCA based the 15 qualitative morphological characters of suggested that 'Pei Chiao', 'Giant Cavendish', and 'Dwarf Cavendish' were close to each other in the PCA scatterplot (Fig. 3a). However, 'Pei Chiao' and 'Giant Cavendish' were closer to each other in the PCA scatterplot, as the results of a PCA with 50 
UPOV-based morphological characters indicated (Fig. 3b). Similar findings were reported by Chang et al., (2017). In summary, 'Dwarf Cavendish', 'Pei Chiao', and 'Giant Cavendish' are phylogenetically related.

A genetic similarity analysis based on the 15 qualitative morphological descriptors suggested that $M$. itinerans var. formosana and $M$. acuminata are in the same cluster but belong to different subclusters (both subclusters had a genetic similarity coefficient of 0.79 ); and $M$. balbisiana belonged to a different cluster from $M$. itinerans var. formosana and M. acuminata (Fig. 2a). In addition, the UPGMA analysis of genetic similarity based on the 50 UPOV-derived morphological characters showed also that $M$. itinerans var. formosana was in the same cluster as M. acuminata but in a different subordinate subcluster from $M$. acuminata and 'Sucrier'; and both subordinate subclusters had a genetic similarity coefficient of 0.52 (Fig. 2b). These analyses did not group $M$. itinerans var. formosana into an independent cluster. However, AFLP can be used to group M. acuminata, $M$. balbisiana, and $M$. itinerans into distinct clusters (Chang et al., 2017; Wong et al., 2002). In summary, this study conducted PCA based on the 15 qualitative descriptors for $M$. acuminata and $M$. balbisiana, the reuslts of which show that $M$. itinerans var. formosana, M. acuminata, and M. balbisiana are in distinct clusters (Fig. 3a), and M. itinerans var. formosana is phylogenetically distant from the other two banana species.

Morphological, biochemical, and molecular characterization of species or cultivars is widely recognized, and morphological characters are used to quantify the genetic characterization of crops (Singh et al., 2015). Multivariate analysis, including PCA and cluster analysis, can be applied in the statistical grouping of germplasm (Ortiz, 1997). The present study found that the 15 morphological characters for M. acuminata and M. balbisiana and 50 UPOV-based morphological characters can be used to cluster the respective species of $M$. acuminata and M. balbisiana and their hybrids. In particular, the PCA based on the 15 morphological characters divided $M$. itinerans var. formosana and the respective species of $M$. acuminata and $M$. balbisiana as well as their hybrids into different dimensional clusters. In summary, by comparing genetic diversity between major banana cultivars and wild banana varieties in Taiwan on the basis of morphological characters, the results of this study are expected to inform the classification, breeding, and germplasm conservation of the banana.

\section{AUTHOR CONTRIBUTIONS}

1. Shu-Fen CHANG, proved Musa species or cultivars of the morphological characters are different, subject to different variables affect the total variance, can analyze the genetic relationship of Musa genotypes, and contribute to the classification of banana germplasm.

2. Yung-Fu YEN, designed the genetic diversity analysis for bananas germplasm research under genetic similarity and principal component analysis for studies, and offered suggestion for research.

3. Jer-Way CHANG, offered suggestion on banana germplasm garden managed by the Taiwan Agricultural Research Institute (Chiayi branch).

4. Ikuo MIYAJIMA, offered advices on international tropical horticultural crops research for the morphological classification research, and revised paper and inspected final data.

5. Kuang-Liang HUANG, organized the research protocol through Musa acuminata and M. balbisiana 15 morphological characters and 50 UPOV-based morphological characters on morphological taxonomy of bananas, and managed lab process.

\section{REFERENCES}

Brandão, L. P., C. P. F. Souza, V. M. Pereira, S. O. Silva, J. A. SantosSerejo, C. A. S. Ledo and E. P. Amorim. 2013 Descriptor selection for banana accessions based on univariate and multivariate analysis. Genet. Mol. Biol. 12: 1603-1620

Byrne, N. 1993 Plant Breeding and the UPOV. RECIEL. 2(2) $136-140$

Chang, S. F., Y. L. Chang, Y. F. Yen, I. Miyajima and K. L. Huang. 2017 Genetic diversity and sectional relationships from an amplified fragment length polymorphism analysis of Taiwan bananas. J. Fac. Agr., Kyushu Univ. 62: 31-37

Channelie're, S., I. Van den houwe, E. Arnaud, J. P. Horry, M. Ruas and N. Roux. 2011 Standardised Procedure for Musa Germplasm Characterisation. Acta Hortic. 897: 113-121

De Langhe, E. 2000 Diversity in the genus Musa: its significance and its potential. Acta Hortic. 540: 81-88

De Langhe, E., M. Pillay, A. Tenkouano and R. Swennen. 2005 Integrating morphological and molecular taxonomy in Musa: the African plantains (Musa spp. AAB group). Plant Sys. Evol. 255: 225-236

FAO. 2003 Overview of world banana production and trade. The World Banana. Economy 1985-2002. Food and Agriculture Organization of the United Nations. Rome. 3-16

FAO. 2014 FAOSTAT database. Food and Agriculture Organization of the United Nations, Rome

Heslop-Harrison, J. S. and T. Schwarzacher. 2007 Domestication, genomics and the future for banana. Ann. Bot. 100: 1073-1084

Iezzoni, A. F. and M. P. Pritts, 1991 Applications of principal component analysis to horticultural research. HortScience. 26 334-338

IPGRI-INIBAP/CIRAD. 1996 Descriptors for banana (Musa spp) IPGRI, Rome, Italy / INIBAP, Montpellier, France / CIRAD, Montpellier, France

Ko, W. H., C. C. Su, C. L. Chen and C. P. Chao. 2009 Control of lethal browning of tissue culture plantlets of Cavendish banana cv. Formosana with ascorbic acid. Plant Cell, Tissue Organ Cult. 96: 137-141

Nsabimana, A. and J van Staden. 2005 Characterization of the banana germplasm collection from Rubona-Rwanda. Sci. Hortic. 107: 58-63

Onyango, M., D. Karamura, S. Keeley, R. Manshardt and D. Haymer. 2011 Morphological Characterisation of East African AAB and AA Dessert Bananas (Musa spp.). Acta Hortic. 897: 95-105

Ortiz, R., 1997 Morphological variation in Musa germplasm. Genet. Resour. Crop Evol. 44: 393-404

Ortiz, R. and D. Vuylsteke. 1998 Quantitative variation and phenotypic correlations in banana and plantain. Sci. Hortic. $\mathbf{7 2}$ $239-253$

Osuji, J. O., B. E. Okoli, D. Vuylsteke and R. Ortiz. 1997 Multivariate pattern of quantitative trait variation in triploid banana and plantain cultivars. Sci. Hortic. 71: 197-202

Rohlf, J. F. $2006 \quad$ NTSYS-pc 2.2 Numerical Taxonomy and Multivariate Analysis System. Version 2.2. Department of Ecology and Evolution, State University of New York, Stony 
Brook.

Simmonds, N. W. and K. Shepherd. 1955 The taxonomy and origins of the cultivated bananas. Bot. J. Linn. Soc. 55: 302-312

Singh, W. A., N. S. Singh, P. J. Handique and H. S. Devi. 2015 Morpho-taxonomical and molecular assessment of Musa genotypes from north-east India by morphological and inter-retrotransposon amplified polymorphism markers. Plant Syst. Evol. 301: 563-575

Swennen, R., D. Vuylsteke and R. Ortiz. 1995 Phenotypic Diversity and Patterns of Variation in West and Central African Plantains (Musa spp., AAB Group Musaceae). Econ. Bot. 49: 320-327
Tezenas du Montcel, H., E. De Langhe and R. Swennen, 1983 Essai de classification des bananiers plantains (AAB). Fruits. 38 $461-474$

UPOV. 2010 Guidelines for the conduct of tests for distinctness, uniformity and stability. Banana (Musa acuminata Colla Musa xparadisiaca L.). TG/123/4. International Union for the Protection of New Varieties and Plants (UPOV), Geneva. p. 45

Wong, C., R. Kiew, G. Argent, S. Ohn, S. K. Lee and Y. Y. Gan. 2002 Assessment of the validity of the Sections in Musa (Musaceae) using AFLP. Ann. Bot. 90: 231-238 